\title{
Anorectal manometry results in defecation disorders
}

\author{
D MOLNAR, L S TAITZ, O M URWIN, AND J K H WALES \\ Department of Paediatrics, University of Sheffield, and Children's Hospital, Sheffield
}

SUMmARY Anorectal manometry and suction biopsy were carried out on 47 children with constipation or soiling, or both. Patients were divided into two groups. Group 1 (37 patients): functional faecal retention, group 2 (10 patients): functional faecal soiling without retention. Ganglion cells or normal acetylcholinesterase staining, or both, was demonstrated in all cases. Normal inhibition of internal sphincter could be achieved by rectal distension in all except 2 children with severe constipation. Resting sphincteric pressures, pressure responses, and conscious rectal sensitivity thresholds were similar in groups 1 and 2, but were increased compared with controls. In group 1 alone, the critical volume increased parallel with conscious rectal sensitivity threshold. Since the complete relaxation of internal sphincter occurs before conscious rectal sensation arises in children with soiling without retention, this may be an important factor, at least in some of the soilers.

Between 10 and $20 \%$ of children referred for gastroenterological consultation have disorders of defecation. Despite this there has been comparatively little research. Consequently it is not clear what investigations are necessary in children with lower bowel dysfunction. This paper contains findings which may help to elucidate whether anorectal manometry and rectal biopsy have a useful role in the diagnosis, prediction of response to conservative management, and prognosis of children with constipation or faecal soiling.

\section{Clinical material and methods}

Eleven control patients were studied, none of whom had a history of bowel dysfunction or neurological disorder. The age range of the controls was 7 months to 16 years, and 6 of them were boys. The diagnoses were enuresis $(n=4)$, failure to thrive $(n=2)$, preoperative ureter implantation to bowel $(n=1)$, asymptomatic diastematomyelia $(n=1)$, irritable detrusor $(n=1)$, preoperative vaginal surgery $(n=1)$, and postoperative bowel resection $(n=1)$.

Table 1 gives the results for the controls and compares them with previously published results.

Forty-seven patients referred with abnormal bowel function (constipation, constipation plus soiling, or soiling alone), were investigated. In every case the diagnosis was not known to the person carrying out the investigation. Thirty-seven were considered to be suffering from functional faecal retention, and 10 from functional faecal soiling without faecal retention. This was assessed from a history of the frequency and amount of stool passed, and an abdominal examination with a rectal examination for the presence of stool in the rectum. Children who passed fewer than 3 stools a week or

Table 1 Control results and comparison with previous figures ${ }^{13}$

\begin{tabular}{|c|c|c|c|c|c|c|c|c|}
\hline & \multicolumn{2}{|c|}{$\begin{array}{l}\text { Control group } \\
\text { (SD; range) }\end{array}$} & $\begin{array}{l}\text { Aaronson } \\
\text { and Nixon } 6\end{array}$ & $\begin{array}{l}\text { Meunier } \\
\text { et al.11 }\end{array}$ & $\begin{array}{l}\text { Meunier } \\
\text { et al. } 10\end{array}$ & $\begin{array}{l}\text { Tobon } \\
\text { et al.12 }\end{array}$ & $\begin{array}{l}\text { Lawson } \\
\text { and Nixon } 1\end{array}$ & $\begin{array}{l}\text { Schuster } \\
\text { et al. } 13\end{array}$ \\
\hline \multicolumn{9}{|l|}{ Resting pressure } \\
\hline Internal & $39 \cdot 1$ & $10 \cdot 7 ; 25-55$ & $32-58$ & 一 & 一 & 一 & 38 & 一 \\
\hline External & $25 \cdot 9$ & $9 \cdot 6 ; 15-40$ & - & - & - & - & - & - \\
\hline RAIRT & $21 \cdot 8$ & $10 \cdot 6 ; 10-40$ & $10-25$ & 15 & $5-30$ & 15 & - & $10-30$ \\
\hline \multicolumn{9}{|l|}{ Response } \\
\hline Internal & $24 \cdot 6$ & $8 \cdot 2 ; 10-35$ & $15-20$ & 一 & - & 一 & 22 & 一 \\
\hline External & 9.6 & $5 \cdot 7 ; 0-20$ & $\overline{0}$ & 一 & 一 & $\overrightarrow{a n}$ & - & - \\
\hline Critical volume & $34 \cdot 8$ & $10 \cdot 7 ; 20-60$ & $25-150$ & $\overline{1}$ & - & 30 & $\overline{\varepsilon 0}$ & - \\
\hline Conscious rectal sensitivity threshold $(n=8)$ & $31 \cdot 9$ & $11 \cdot 9 ; 10-50$ & 一 & 14 & $3-31$ & 一 & 150 & - \\
\hline -Critical volume & -5 & $3 \cdot 3 ; 0-20$ & 一 & 一 & 一 & 一 & - & 一 \\
\hline
\end{tabular}

RAIRT $=$ rectoanal inhibitory resfonse threshold. 
were found to have persistent accumulation of faeces were classified as constipated.

A manometry method based on a balloon system was used as described by Lawson and Nixon ${ }^{1}$ and converted to a water-filled system according to Clayden and Lawson. ${ }^{2}$ Probes made of turned brass and stainless steel tubes consist of 4 rubber-covered chambers $1 \times 0.5 \mathrm{~cm}$. These record at $1 \mathrm{~cm}$ intervals through the anal canal. A thin latex balloon is mounted $4 \mathrm{~cm}$ proximal to the 4 th centimeter chamber and is used for pressure measurement and rectal distension. We used only 2 chambers lying in the external and internal sphincter levels and the rectal balloon for pressure measurements. The chambers and the rectal balloon are connected to transducers by nylon tubes and via amplifiers to the ultraviolet recorder SE oscillograph 3006. The pressures at rest, and changes of pressure in the anal canal with rectal distension were recorded. In addition rectoanal inhibitory response threshold (RAIRT) - that is the distension volume at which a minimal relaxation of $10 \mathrm{cmH}_{2} \mathrm{O}$ occurs, critical volume $(\mathrm{CV})$-namely the volume at which internal sphincter remains relaxed, and conscious rectal sensitivity threshold (CRST) were determined if possible, taking the average of 2 or 3 trials for each subject. The test was carried out in children lying in the left lateral or supine position. Small children occasionally required sedation or ketamine anaesthesia. Suction biopsy was carried out after the manometry; specimens taken at $5,4,3 \mathrm{~cm}$ levels from the anal verge were examined for ganglion cells with light microscopy and stained for acetylcholinesterase. ${ }^{3}$

\section{Results}

Clinical features of patients. The distribution of the patients according to age and gender is shown in Table 2. Most of the children were aged between 3 and 12 years. Defecation disorders were three times more common in boys. The onset of constipation or soiling is also shown in Table 2. The onset of symptoms was under age 7 years in $43(91 \%)$ patients. The main complaint in 4 patients was constipation, in 28 constipation and soiling, and in 15 soiling alone. The symptoms were due to

Table 2 Age and gender distribution of patients and age at onset of constipation

\begin{tabular}{lccccccc}
\hline & Total & \multicolumn{2}{c}{ Years } \\
\cline { 2 - 7 } & & $0-3$ & $4-6$ & $7-9$ & $10-12$ & >12 \\
\hline Boys & 35 & 2 & 7 & 16 & 9 & 1 \\
Girls & 12 & - & 4 & 4 & 3 & 1 \\
Age at onset & 47 & 30 & 13 & 4 & -1 & - \\
\hline
\end{tabular}

functional faecal retention in 37 patients, functional faecal soiling without retention in 10 patients. The incidence of other characteristic symptoms is shown in Table 3. Abdominal pain was the most common associated finding. Positive family history was present in $4(8.5 \%)$ patients.

Manometry. Patients were divided into two groups according to the underlying disorder, group 1 patients with functional faecal retention, group 2 faecal soilers without retention. Resting pressures (Table 4) showed higher values in the constipated and soiling groups, possibly a manifestation of hypertrophy of bowel muscle. External sphincter contraction and internal sphincter relaxation were observed in all but 2 children. The 2 children who failed to show internal sphincter relaxation were severely constipated. RAIRT was largely in the control range in group $1(29 \pm 2 \cdot 6)$ and group 2 $(25 \pm 3.6 \mathrm{ml})$ but with more scatter in group 1 , where the RAIRT was above the normal range in 6 $(16.2 \%)$ children (Fig. 1).

In group 1, $29(78 \%)$ CRST values were above the normal limit with a mean value of $118 \pm 11 \cdot 8$.

Table 3 Symptoms and signs of patients

\begin{tabular}{lll}
\hline Symptoms and signs & Patients & \\
\cline { 2 - 3 } & No & $\%$ \\
\hline Abdominal pain & 30 & 64 \\
Stool difficult to evacuate & 29 & 62 \\
Hard stool & 27 & 58 \\
Abdominal mass & 23 & 49 \\
Big stool & 22 & 47 \\
Abdominal distension & 18 & 38 \\
Small stool & 16 & 34 \\
Rectal bleeding & 11 & 23 \\
Poor appetite & 12 & 26 \\
Episodic diarrhoea & 6 & 13 \\
Urinary incontinence & 7 & 15 \\
Nausea and vomiting & 4 & $8 \cdot 5$ \\
\hline
\end{tabular}

Table 4 Resting pressure and pressure response

\begin{tabular}{|c|c|c|c|c|}
\hline & \multicolumn{2}{|c|}{ Resting pressure } & \multicolumn{2}{|c|}{$\begin{array}{l}\text { Pressure response } \\
\text { (drop in pressure) }\end{array}$} \\
\hline & Internal & External & Internal & External \\
\hline $\begin{array}{l}\text { Control }(n=11) \\
\text { Mean } \\
\text { SE } \\
\text { Range }\end{array}$ & $\begin{array}{r}39 \cdot 1 \\
\pm 3 \cdot 1 \\
25-55\end{array}$ & $\begin{array}{c}25 \cdot 9 \\
\pm 3 \\
15-40\end{array}$ & $\begin{array}{r}24 \cdot 6 \\
\pm 2 \cdot 5 \\
10-35\end{array}$ & $\begin{array}{r}9.6 \\
\pm 1.7 \\
0-20\end{array}$ \\
\hline $\begin{array}{l}\text { Group } 1(n=37) \\
\text { Mean } \\
\text { SE } \\
\text { Range }\end{array}$ & $\begin{array}{r}56 \cdot 2 \\
\pm 2 \cdot 7 \\
30-80\end{array}$ & $\begin{array}{r}41 \cdot 2 \\
\pm 2 \cdot 2 \\
15-80\end{array}$ & $\begin{array}{r}33 \cdot 1 \\
\pm 2 \cdot 1 \\
10-55\end{array}$ & $\begin{array}{r}22 \cdot 2 \\
\pm 1 \cdot 7 \\
10-45\end{array}$ \\
\hline $\begin{array}{l}\text { Group 2 }(n=10) \\
\text { Mean } \\
\text { SE } \\
\text { Range }\end{array}$ & $\begin{array}{r}49 \cdot 5 \\
\pm 4 \cdot 3 \\
40-70\end{array}$ & $\begin{array}{r}37.5 \\
\pm 2.5 \\
30-50\end{array}$ & $\begin{array}{r}32 \cdot 2 \\
\pm 3 \cdot 9 \\
10-50\end{array}$ & $\begin{array}{r}27 \cdot 1 \\
\pm 3 \cdot 8 \\
15-45\end{array}$ \\
\hline
\end{tabular}




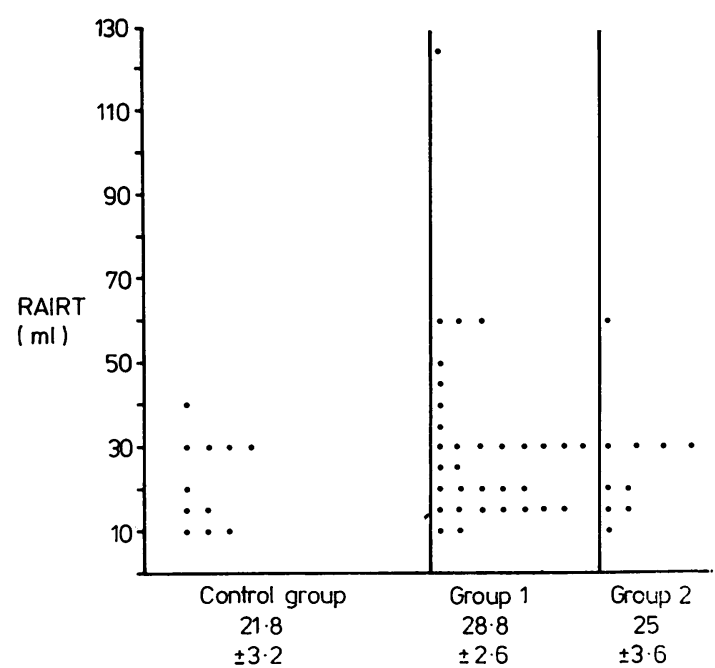

Fig. 1 Individual rectoanal inhibitory response threshold values in the 3 groups of patients.

The highest mean CRST was present in group 2 $(175 \pm 22 \cdot 1)$ where all values were above the normal upper limit (Fig. 2). The CRST was significantly higher $(P<0 \cdot 001)$ in group 1 and group 2 compared with controls, and in group 2 compared with group 1 $(\mathrm{P}<0.05)$.

The individual CV values are shown in Fig. 2 and were increased in $20(54 \%)$ cases from group 1 and in $5(50 \%)$ cases from group 2 . The means $\pm \mathrm{SE}$ of $\mathrm{CV}$ were $117 \pm 11 \cdot 6,102 \pm 16 \cdot 5$ respectively. The mean value of $\mathrm{CV}$ was significantly higher in groups 1 and 2 than in controls $(34.8 \pm 3 \cdot 2)(P=0.001)$.

The individual differences between CRST and CV are also plotted in Fig. 2. CRST-CV mean values in controls and groups 1 and 2 were $-5 \pm 3 \cdot 3,1 \cdot 1 \pm$ $4 \cdot 8,73 \pm 21.6$ respectively. The CRST-CV mean value was significantly higher $(P<0.001)$ in group 3 than in the other groups. This means that conscious rectal sensation and complete internal sphincter relaxation occurs nearly simultaneously in controls and in group 1 , while in group 2 the complete relaxation of internal sphincter precedes the conscious sensation.

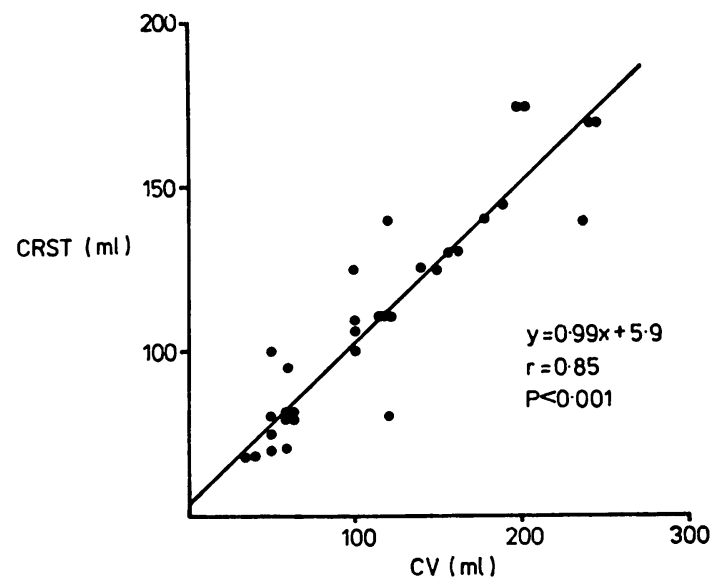

Fig. 3 Correlation between conscious rectal sensitivity threshold and critical volume values in children with functional faecal retention (group 1).
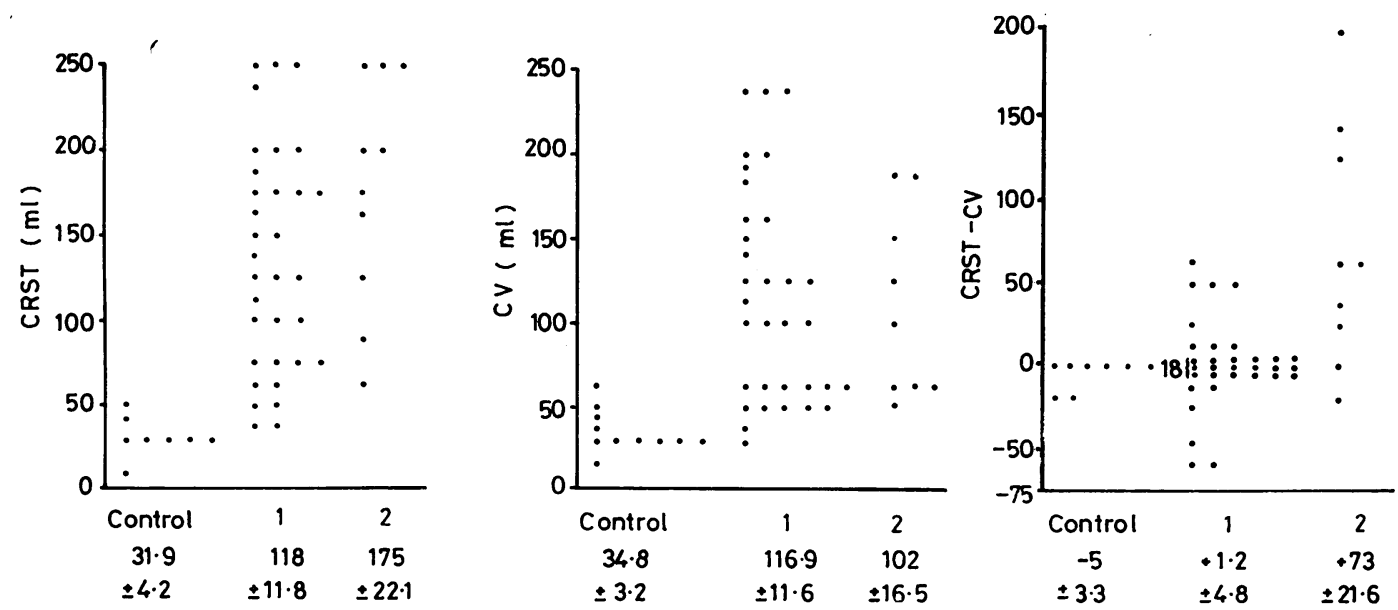

Fig. 2 Individual values of conscious rectal sensitivity threshold, critical volume, and conscious rectal sensitivity threshold-critical volume in the 3 groups of patients. 


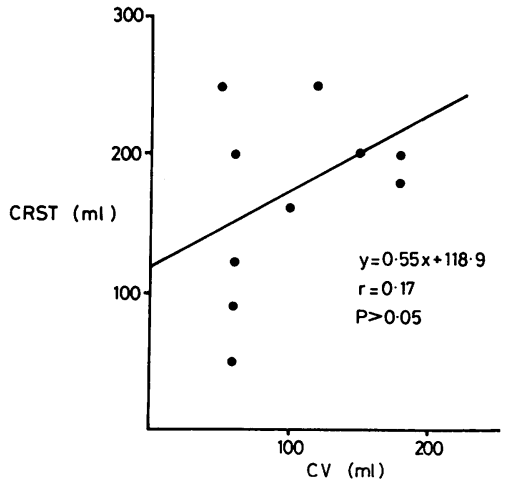

Fig. 4 Correlation between conscious rectal sensitivity threshold and critical volume values in children with functional faecal soiling without retention (group 2).

CRST shows a statistically highly significant positive correlation with $\mathrm{CV}$ in children with functional faecal retention (Fig. 3). This correlation does not exist in children with functional faecal soiling without retention (Fig. 4).

\section{Discussion}

The rectoanal reflex was first shown in 1878 by Gowers ${ }^{4}$ and reported in 1964 by Callaghan and Nixon ${ }^{5}$ to be absent in Hirschsprung's disease. Since then the reliability of anorectal manometry as a diagnostic technique in defecation disorders has been proved. ${ }^{6-912}$ The high frequency of abnormal results and Hirschsprung's disease in previous manometry studies of constipated patients, $43 \%,{ }^{6} 9.4 \%,{ }^{2}$ and $10 \%,{ }^{9}$ would justify the use of anorectal manometry in lower bowel disorders. However, these patients were highly selected.

No Hirschsprung's disease was found in 47 children referred to our clinic with constipation or soiling. This does not confirm the earlier reported high incidence of Hirschsprung's disease in children with constipation, probably because our patients were unselected.

The resting sphincteric pressures and pressure responses measured in the controls are equivalent to other published figures (Table 1). In groups 1 and 2 the resting values are slightly higher. This could be due to hypertrophy of the bowel muscle as a response to chronic overloading, but is difficult to explain in the patients without faecal retention. Two severely constipated children failed to show any relaxation of the internal sphincter. This is a well-known phenomenon in chronic constipation. ${ }^{6} 8$

RAIRT was increased in some children with faecal retention. This accords with the findings of
Meunier et al..$^{10}$ The significance of an increased RAIRT is not known. Many of the investigated children with faecal rention had high CRST as a consequence of megarectum.

Although CV increases parallel with CRST the normal or slightly increased RAIRT and high CRST still produces a situation conducive to soiling in constipated children, as stated earlier by Meunier et al. ${ }^{11}$ The increased CRST in soiling patients without faecal retention and megarectum is an unexpected finding and has not previously been reported. The high CRST may be the primum movens in some of these patients, or may be secondary to psychogenic factors. The CV does not follow the increase in CRST and the difference between CRST and CV may be an important factor in soiling, when it occurs without faecal retention, but more detailed investigations are needed to draw final conclusions.

These findings seem to suggest that routine manometric and biopsy studies on unselected patients with lower bowel dysfunction are unlikely to yield many cases of organic or 'physiological' disease. Perhaps only cases very resistant to conservative management should be investigated. The development of an effective method for selection of patients for manometry would be useful.

\section{Addendum}

Since these data were analysed a further 20 children have been studied with similar results. No case of Hirschsprung's disease has been detected in 67 successive subjects.

This study was made possible by grants from the Hawley Trust and the NHS Locally Organised Research Grant (Trent RHA), and has the approval of the Ethics Committee of the Sheffield Southern District Health Authority.

\section{References}

1 Lawson J O N, Nixon H H. Anal canal pressures in the diagnosis of Hirschsprung's disease. J Pediatr Surg 1967; 2: 544-52.

2 Clayden G S, Lawson J O N. Investigations and management of long-standing chronic constipation in childhood. Arch Dis Child 1976; 51: 918-23.

${ }^{3}$ Lake B D, Puri P, Nixon H H, Claireaux A E. Hirschsprung's disease. An appraisal of histochemically demonstrated acetylcholinesterase activity in suction rectal biopsy specimens as an aid to diagnosis. Arch Pathol Lab Med 1878; 102: 244-7.

4 Gowers V R. The automatic action of the sphincter ani. Proc Roy Soc Lond 1878; 26: 77-84.

5 Callaghan R P, Nixon H H. Megarectum: physiological observations. Arch Dis Child 1964; 39: 153-7. 
6 Aaronson I, Nixon H H. A clinical evaluation of anorectal pressure studies in the diagnosis of Hirschsprung's disease. Gut 1972;13: 138-46.

7 Schnaufer L, Talbert J L, Haller J A, Reid N C R W, Tobon F, Schuster M M. Differential sphincteric studies in the diagnosis of ano-rectal disorders of childhood. J Pediatr Surg 1967; 2: 538-43.

8 McParland F A, Olness K. Diagnostic uses of anorectal manometry in pediatrics. Minn Med 1979; 62: 447-50.

9 Shaw A, Bosher P, Blair K. Anorectal manometry for evaluating defecation disorders. Va Med 1980; 107: 366-70.

10 Meunier P, Marechal J M, De Beaujeu M J. Rectoanal pressures and rectal sensitivity studies in chronic childhood constipation. Gastroenterology 1979; 77: 330-6.

11 Meunier P, Mollard P, Marechal J M. Physiopathology of megarectum: the association of megarectum with encopresis. Gut 1976; 17: 224-7.

12 Tobon F, Reid N, Talber J L, Schuster M M. Nonsurgical test for the diagnosis of Hirschsprung's disease. N Engl J Med 1968; 278: 188-94.

13 Schuster M M, Hookman P, Hendrix T R, Mendeloff A. Simultaneous manometric recording of internal and external anal sphincteric reflexes. Bull John Hopkins Hosp 1965; 116: 79-88.

Correspondence to Dr L S Taitz, Department of Paediatrics, Children's Hospital, Sheffield S10 2TH.

Received 14 December 1982

\section{Notice to contributors}

Please note that revised guidelines for the submission of manuscripts have been printed inside the front cover of this journal and, in particular, that two copies of papers should be submitted. 